\title{
A rare case of Acute Lymphocytic Leukemia (ALL) presenting with double Philadelphia chromosome - relapse or secondary leukemia?
}

\author{
Mireille Guimarães Vaz de Campos, Maria de Lourdes L. Ferrari Chauffaille, Celso Arrais Rodrigues, \\ Everson A. Krum and Mihoko Yamamoto \\ Disciplina de Hematologia e Hemoterapia - UNIFESP/EPM, São Paulo, SP, Brazil.
}

\begin{abstract}
The Philadelphia chromosome is observed in $5 \%$ of pediatric acute lymphocytic leukemia (ALL) and in $25 \%$ to $50 \%$ of adult ALL cases, and is associated with poor prognosis. Double $\mathrm{Ph}$ in a hyperdiploid karyotype is common in chronic myeloid leukemia (CML), but rarely found in ALL. We report here the case of a girl diagnosed with ALL at 7 years of age. After treatment with the pediatric protocol BFM 83 for ALL, she stayed in continuous complete remission for nine years. At age 19, she was re-admitted with a white blood cell count of $6.8 \times 10^{9} / \mathrm{L}$ with $3 \%$ blasts, and a platelet count of $65 \times 10^{9} / \mathrm{L}$. Bone marrow aspirate showed $92.6 \%$ lymphoid blast cells, and chromosome analysis after G-banding revealed the karyotype $51, X X,+? 5, t(9 ; 22)(q 34.1 ; q 11.2),+16,+20,+21,+\operatorname{der}(22) t(9 ; 22)(q 34.1 ; q 11.2)[10] / 46, X X[1]$. FISH analysis for the BCR/ABL fusion showed $56 \%$ of interphase cells with two fusion signals, $30 \%$ with one, and $6 \%$ with three. Double $\mathrm{Ph}$ is rare in relapsed leukemia, and the possibility of secondary leukemia cannot be ruled out.
\end{abstract}

Key words: relapsed acute lymphocytic leukemia, double Philadelphia chromosome.

Received: October 10, 2002; Accepted: May 21, 2003.

\section{Introduction}

The Philadelphia ( $\mathrm{Ph}$ ) chromosome, the hallmark genetic lesion of chronic myeloid leukemia (CML), is less frequently found in acute lymphocytic leukemia (ALL) and rarely in acute myelogenous leukemia (AML). It is present in only $5 \%$ of the pediatric and $25 \%$ to $50 \%$ of the adult ALL cases, and is associated with poor prognosis (SeckerWalker et al., 1991). Additional cytogenetic aberrations are described in $41 \%$ to $86 \%$ of patients with $\mathrm{Ph}+$ ALL. A hyperdiploid karyotype, defined by the presence of more than 50 chromosomes, is detected in $2 \%$ to $9 \%$ of adult ALL patients and in $29 \%$ of pediatric patients (Ritterbach et al., 1998; Wetzler et al., 2000). Translocation $\mathrm{t}(9 ; 22)$ is a common structural aberration found in patients with hyperdiploidy (37\% and 64\%, respectively) (The Groupe Français de Cytogénétique Hématologique, 1996; Faderl et al., 2000).

The BCR/ABL breakpoint varies according to the type of leukemia. CML is almost always associated with the $\mathrm{p} 210^{\mathrm{BCR} / \mathrm{ABL}}$ variant. In pediatric $\mathrm{Ph}+\mathrm{ALL}$, nearly $90 \%$ of cases have the p190 variant, but in adult ALL approximately $25 \%$ to $50 \%$ of cases are p $210^{\mathrm{BCR} / \mathrm{ABL}}$ (Secker-

Send correspondence to Maria de Lourdes L. Ferrari Chauffaille. Departamento de Hematologia e Hemoterapia - UNIFESP/EPM, Rua Botucatu, 740, 04023-900 São Paulo, SP, Brazil. E-mail: chauffaill@ hemato.epm.br.
Walker et al., 1991). In fact, the so-called $\mathrm{Ph}+$ ALL seems to be a heterogeneous disease including: (1) lymphoid lineage-restricted ALL that can be either $\mathrm{p} 190$ or $\mathrm{p} 210^{\mathrm{BCR} / \mathrm{ABL}}$, although most cases have been $\mathrm{p} 190^{\mathrm{BCR} / \mathrm{ABL}}$, (2) stem cell ALL, with evidence of disease in both lymphoid and myeloid lineages, that can either be $\mathrm{p} 190$ or $\mathrm{p} 210^{\mathrm{BCR} / \mathrm{ABL}}$, (3) misclassified CML in lymphoid blast crisis, which is a stem cell disease and mainly $\mathrm{p} 210^{\mathrm{BCR} / \mathrm{ABL}}$ (Radich et al., 2001).

We report a case of relapsed ALL associated with double Philadelphia chromosome in a patient who had been diagnosed with ALL at 7 years of age and had stayed in remission for nine years.

\section{Case Report}

A 7-year-old girl was admitted to HSP/UNIFESP in October 1989 with widespread adenopathy and weight loss. On physical exam she showed submandibular, cervical, axilar and inguinal adenopathies, besides splenomegaly. Peripheral blood tests revealed $8.4 \mathrm{~g} / \mathrm{dL}$ of hemoglobin, a white blood cell count of $28.6 \times 10^{9} / \mathrm{L}$ with $78 \%$ blast cells, and a platelet count of $90 \times 10^{9} / \mathrm{L}$. Bone marrow aspirate was hypercellular, with $90 \%$ blast cells of the FAB L2 subtype, and peroxidase-negative. Immunophenotyping showed CD19+, CD10+, CD13- and CD33-. The patient was treated according to the children ALL BFM 83 protocol (Riehn. et al., 1990), and achieved complete remission 
after induction. She completed the whole protocol by May 1992 and stayed nine years out of treatment. In November 2001, at the age of 19 , she was admitted complaining of leg pain, echimosis, fever, and anorexia. There were no abnormal physical findings other than echimosis. Peripheral blood tests revealed $12.3 \mathrm{~g} / \mathrm{dL}$ of hemoglobin, a white blood cell count of $6.8 \times 10^{9} / \mathrm{L}$ with $3 \%$ blasts, and a platelet count of $65 \times 10^{9} / \mathrm{L}$. Bone marrow aspirate was hypercellular, with $92.6 \%$ lymphoblasts, which were morphologically similar to those observed at the first diagnosis, and were peroxidase-negative. Flow cytometry immunophenotyping showed: $\mathrm{CD} 10+, \mathrm{CD} 19+, \mathrm{CD} 13+, \mathrm{CD} 33+$. Cytoplasm and surface immunoglobulins were negative. Chromosome analysis revealed a $51, \mathrm{XX},+? 5, \mathrm{t}(9 ; 22)(\mathrm{q} 34.1$; $\mathrm{q} 11.2),+16,+20,+21,+\operatorname{der}(22) \mathrm{t}(9 ; 22)(\mathrm{q} 34.1 ; \mathrm{q} 11.2)[10] / 46$, XX[1] karyotype. RT-PCR showed the p190 ${ }^{\mathrm{BCR} / \mathrm{ABL}}$ variant. FISH performed for the BCR/ABL rearrangement showed $56 \%$ of cells with two BCR/ABL fusion signals, $30 \%$ with one signal, and $6 \%$ with three signals $(200$ interphase cells were counted by each of two observers). The patient was treated with Prednisone (D1-21), Vincristine (D1, 8, 15), Daunorubicine (D1, 8, 15), and L-asparaginase (D7-8, D14-15). A bone marrow aspirate performed on day 14 after induction had $71 \%$ blasts, and she was scheduled for the Hyper-CVAD regimen (Garcia-Manero et al., 2000). In spite of the treatment, she developed hepatosplenic candidiasis and cerebellar toxicity probably due to cytarabine, and died in sepsis without remission in February 2002.

\section{Discussion}

We describe here the rare case of a young female patient with double $\mathrm{Ph}$ chromosome and ALL diagnosed twelve years after the first ALL diagnosis, and after nine years of complete remission. The main question is whether her leukemia was secondary to the treatment received twelve years earlier or a true relapsed leukemia.

Patients with $\mathrm{Ph}$ chromosomes treated only with conventional chemotherapy have a poor long-term survival. Although $72 \%$ to $97 \%$ of the pediatric $\mathrm{Ph}+$ cases achieve complete remission (CR) after induction therapy, the 5 -year event-free survival (EFS) ranges from $10 \%$ to $20 \%$, vs. $76 \%$ in the $\mathrm{Ph}$-negative population. Failure is due mainly to recurrent disease, and the poor prognosis persists after stratification in a high-risk treatment protocol. In adult $\mathrm{ALL}$, the $\mathrm{CR}$ rate of $\mathrm{Ph}+$ patients is generally similar to that of Ph-negative patients (60\% to $80 \%)$. Nevertheless, the duration of remission is usually shorter ( $<12$ months) and forces the EFS rate towards $10 \%$, vs. $28 \%$ to $39 \%$ for the whole group of adult ALL (Garcia-Manero et al., 2000; Radich et al., 2001).

Hyperdiploid karyotypes with double $\mathrm{Ph}$ are common in CML, with over five hundred reported cases. In contrast, they are rare in ALL, and a total of 66 cases with double $\mathrm{Ph}$ are reported in Mitelman's Catalog of Chromosome Aber- rations in Cancer (http://cgap.nci.nih.gov/Chromosomes/ CytSearchForm). Of those, only 23 were associated with hyperdiploidy and, interestingly, only three patients showed more than two copies of the Ph chromosome on conventional karyotyping. In a series of 66 karyotypes of $\mathrm{Ph}+\mathrm{ALL}$ patients, Rieder et al. (1996) found eight cases with double $\mathrm{Ph}(12 \%)$, but only three $(9 \%)$ were hyperdiploid. Therefore, since $\mathrm{Ph}+$ cases represent approximately $25 \%$ of ALL, cases with double Ph should represent a smaller percentage of adult ALL. Thomas et al. (1998) found seven cases of double $\mathrm{Ph}$ in $41 \mathrm{Ph}+\mathrm{ALL}$ $(17 \%)$, and the presence of an extra Ph chromosome was considered an initial parameter associated with a statistically significant worse prognosis. Uckun et al. (1998) studied 1,322 children with ALL, and found $30 \mathrm{Ph}+$ patients, four of whom had double $\mathrm{Ph}$, corresponding to $13 \%$ of $\mathrm{Ph}+$ ALL and to $0.03 \%$ of pediatric ALL.

It has been recognized that ALL shows significant immunophenotypic and karyotypic diversity. Moreover, ALL patients frequently undergo karyotype and immunophenotype changes at the time of relapse. Clonal evolution is not the only cytogenetic observation at relapse; some cases show entirely different karyotypes, thereby raising the possibility of secondary leukemia (Raimondi SC, 1993). Chucrallah et al. (1995) analyzed 32 relapsed adult ALL patients and found that nine (28\%) had clonal evolution, $12(37 \%)$ had a different karyotype, and 11 (34\%) had an unchanged karyotype.

FISH analysis performed in the present case showed the double BCR/ABL fusion signals in the majority of interphase cells, and rare cells with three fusion signals. Unfortunately, FISH could not be performed on marrow smear from the first diagnosis stored in a common file at room temperature, and thus it was not possible to clarify if the patient was $\mathrm{Ph}+$ at first diagnosis. However, this possibility is unlikely, because the patient stayed in remission and out of treatment for nine years following conventional chemotherapy, whereas the outcome of $\mathrm{Ph}+\mathrm{ALL}$ cases is highly unfavorable. Although the phenotype change (acquired $\mathrm{CD} 13$ and $\mathrm{CD} 33$ ) and the probably acquired $\mathrm{Ph}+\mathrm{fa}-$ vor the hypothesis of a secondary leukemia, the doubt remains whether the second disease could be a relapsed ALL with clone evolution.

\section{References}

Chucrallah AE, Stass SA, Huh YO, Albitar M and Kantarjian HM (1995) Adult acute lymphoblastic leukemia at relapse. Cytogenetic, immunophenotypic, and molecular changes. Cancer 76:985-991.

Faderl S, Kantarjian HM and Thomas DA (2000) Outcome of Philadelphia chomosome-positive acute lymphoblastic leukemia. Leuk Lymphoma 36:263.

Garcia-Manero G and Kantarjian HP (2000) The Hyper-CVAD regimen in adult acute lymphocytic leukemia. Hematol Oncol Clin North Am 14:1381-1396. 
Mitelman F (2002) Catalog of chromosome Aberrations in Cancer. http://cgap.nci.nih.gov/Chromosomes/CytSearchForm.

Radich JP (2001) Philadelphia chomosome-positive acute lymphocytic leukemia Hematol. Oncol. Clin. North Am 5:2135 .

Raimondi SC, Pui C-H, Head DR, Rivera GK and Behm FG (1993) Cytogenetically different leukemic clones at relapse of childhood acute lymphoblastic leukemia. Blood 82:57680 .

Rieder H, Ludwig W-D, Gassmann W, Maurer J, Janssen JWG, Gökbuget N, Schwartz S, Thiel E, Löffler H, Bartram CR, Hoelzer D and Fonatsch C (1996) Prognostic significance of additional chromosome abnormalities in adult patients with Philadelphia chromosome positive acute lymphoblastic leukaemia. Br J Haematol 95:678-691.

Riehn H, Gadner H, Henze G, Kornhuber B, Lampat F, Niethammer D, Reiter A and Schellong G (1990) Results and significance of six randomized trials in four consecutive ALL-BFM studies. Haematol Blood Transfus 33: 439.

Ritterbach J, Hiddemann W, Beck JD, Schrappe M, Janka-Schaub G, Ludwig WD, Harbott J and Lampert F (1998) Detection of hyperdiploid karyotypes ( $>50$ chromosomes) in child- hood acute lymphoblastic leukemia (ALL) using fluorescence in situ hybridization (FISH). Leukemia 12:427-33.

Secker-Walker LM, Craig JM and Hawkins JM (1991) Philadelphia positive acute lymphoblastic leukemia in adults: age distributions, BCR breakpoint and prognostic significance. Leukemia 5:196-199

The Groupe Français de Cytogénétique Hématologique (1996): Cytogenetic abnormalities in adult acute lymphoblastic leukemia: Correlations with hematologic findings and outcome. A collaborative study of the Groupe Français de Cytogénétique Hématologique. Blood 87:3135.

Thomas X, Thiebaut A, Olteanu N, Danaila C, Charrin C, Archimbaud E and Fiere D (1998) Philadelphia chromosome positive adult acute lymphoblastic leukemia: characteristics, prognostic factors and treatment outcome. Hematol Cell Ther 40:119-128.

Uckun FM, Nachman JB, Sather HN, Sensel MG, Kraft P, Steinherz PG, Lange B, Hutchinson R, Reaman GH, Gaynon PS and Heerema NA (1998) Clinical significance of Philadelphia chromosome positive pediatric acute lymphoblastic leukemia in the context of contemporary intensive therapies. A Report from the Childrens Cancer Group. Cancer 83:2030-2039.

Wetzler M (2000) Cytogenetics in adult acute lymphocytic leukemia. Hematol Oncol Clin North Am 14:1237-1249. 